\title{
Creche em ambiente urbano pobre: ressonâncias no ecossistema desenvolvimental ${ }^{1}$
}

\author{
Lúcia Vaz de Campos Moreira \\ Eulina da Rocha Lordelo \\ Universidade Federal da Bahia
}

\begin{abstract}
Resumo
O presente trabalho teve como objetivo discutir a relação entre creche e família, à luz dos resultados de uma investigação empírica sobre as condições de vida de uma população usuária de creche. $\mathrm{O}$ estudo utilizou as informações fornecidas por 90 mães de crianças freqüentando duas creches em bairro pobre de Salvador, coletadas em questionário e entrevista. Os resultados evidenciam condições de vida muito precárias, com prováveis repercussões sobre a qualidade do cuidado oferecido à criança, caracterizando uma situação de vulnerabilidade e risco ao desenvolvimento da criança. Discute-se o papel da creche em intermediar e apoiar políticas públicas de promoção social, bem como de interferência nos ciclos de perpetuação de pobreza e violência, capazes de afetar o desenvolvimento saudável da criança.

Palavras chave: creche, família, comunidade, pobreza
\end{abstract}

\begin{abstract}
Crèche in a poor urban neighborhood: echoes on developmental ecosystem

This work aimed to discuss the relationship between crèche and family, using data from an empirical investigation on life conditions of crèche' users. The study used information from 90 mothers of children enrolled in two day-care centers in a poor neighborhood in Salvador. The information was gathered through questionnaire and interview. The results show very precarious living conditions, with probable repercussions on the quality of home care for the child. This characterizes a situation of high risk and vulnerability for the child's early development. In this paper, the day care center is thought as an intermediary unit, which can foster and sustain public policies to promote social equality, as well as to prevent the perpetuation of poverty and violence cycle, having a positive effect on the well being and development of children.

Keywords: crèche, family, community, poverty.
\end{abstract}

A creche como instituição no Brasil vem passando por uma lenta transformação, de organizações de caridade para guarda das crianças pobres para uma instituição social de amplo alcance, orientada por um modelo educacional. Embora a implantação desse modelo esteja apenas no início, há um consenso entre os especialistas, refletido nos textos legais, sobre a desejabilidade de atingir um estado no qual a educação infantil seja um direito de toda criança, independente de suas condições socioeconômicas, sem o caráter compensatório e/ou remediativo aplicável a políticas de assistência social, de redução da pobreza, incremento de políticas de saúde etc. Trata-se de reconhecer a educação infantil como um fim em si mesma, com repercussões sobre o bem-estar atual da criança e parte integrante do seu processo de educação (Ros- setti-Ferreira, Amorim e Vitória, 1994).

Este artigo pretende, a partir de uma perspectiva ecológica (Bronfenbrenner, 1996; 1995), explorar as possibilidades de repercussão da educação infantil em outras áreas da vida social, para as quais as políticas públicas estão (ou, pelo menos, devem estar) voltadas. Reconhecendo a especificidade da educação infantil, sua identidade por direito próprio, pretende-se, contudo, deslocar o foco dos estudiosos e formuladores de políticas para alguns aspectos subsidiários, mas não irrelevantes, das ações das creches, com o objetivo de discutir os laços entre estas ações e a família, estendendo-se a análise até os contextos sociais em que estão inseridas.

Não é possível, em princípio, considerar o problema da creche independentemente dos contextos sociais relacionados. Historicamente, os estilos de cuidado à criança sempre acompanharam as condições de subsistência das sociedades (Lamb e Sternberg, 1992). Conforme esses autores, o fato de que os psicólogos costumam estudar os efeitos da creche no desenvolvimento da criança pode dar a impressão de que essa forma de cuidado foi planejada visando ao bem estar das crianças. Na verdade, as creches existem, em primeiro lugar, porque ambos os pais têm 
que trabalhar fora de casa e não podem assumir o cuidado de seus filhos simultaneamente. Nas sociedades industriais contemporâneas, é a entrada da mulher na força de trabalho, em unidades distantes de sua casa, que tem impulsionado a sociedade e os governos em busca de soluções de guarda e de educação da criança.

Pode-se sustentar que a demanda por creches no Brasil responde a três tipos de necessidades sociais: o primeiro tipo é, sem dúvida, a liberação da mulher para o ingresso no mercado de trabalho, sem que seus filhos sejam prejudicados. $\mathrm{O}$ trabalho da mulher vem sendo visto, nos últimos 50 anos, como uma condição importante para se atingir uma igualdade entre os sexos, em termos de direitos. O segundo tipo de necessidade está ligado às mudanças na estrutura da família, crescentemente nuclear ou mono-parental, condição em que não há mais avós ou outros parentes capazes de substituir os pais no cuidado à criança pequena. Finalmente, a creche responde às condições de extrema pobreza de grande número de famílias ocupando as periferias das grandes cidades, com habitações extremamente precárias, em termos de saneamento básico, espaço, segurança, equipamentos e materiais, as quais pressionam o Estado a fornecer condições de cuidado mais apropriadas ao desenvolvimento.

Paralelamente a essas condições socioeconômicas que impulsionam a demanda por creches, pode-se identificar as idéias de políticas sociais direcionadas para reduzir a pobreza através da educação, consubstanciadas na agora desacreditada teoria da educação compensatória. Por exemplo, Connel (1995) assinala o surgimento da noção de cultura da pobreza nos meios urbanos, o que teria afetado diretamente o conceito de educação compensatória em países ricos, com repercussões também no Brasil, particularmente a partir da década de 70 , momento em que a educação passou a ser concebida como meio através do qual o subdesenvolvimento poderia ser superado e o progresso acelerado. $\mathrm{Na}$ visão da educação compensatória, os programas de rápida preparação para a entrada no primeiro grau resolveriam os problemas dos déficits culturais das crianças pobres (Sousa, 1996).

Para Connell (1995), os principais pressupostos para tais programas seriam: a) o problema está relacionado apenas a uma minoria em desvantagem; b) no que diz respeito à cultura ou atitudes, o pobre se diferencia da maioria; e c) a correção da desvantagem na educação seria um problema técnico. $\mathrm{O}$ autor contesta esses pressupostos, acreditando que os fatos demonstram pouca evidência de que os pobres não têm interesse semelhante ao de outras pessoas para com as crianças ou a educação. Inclusive, a escola mostra-se, para a classe trabalhadora, como a maior portadora de esperanças para um futuro melhor. Da mesma forma, Sena (1990), conforme citado em Geis (1994), menciona ser uma inverdade que os pais das camadas populares apresentem descaso e desinteresse pela educação. Segundo a autora, mesmo sendo idealizadas as representações de educação que estes pais possuem, eles demonstram estar interessados e empenhados no de- senvolvimento de seus próprios filhos.

Também Geis (1994), em estudo relativo a representações de mães e educadoras sobre o papel da creche, comenta que, mesmo ao manifestarem grande preocupação com a segurança das crianças, as mães demonstram estar conscientes de sua responsabilidade pela criação dos filhos, na medida em que apenas se tranquiilizam quando os filhos se encontram em local seguro, com pessoas qualificadas, capazes de cuidar da criança.

Parece, então, que a rejeição às idéias de educação compensatória e seus pressupostos se deu com base no seu caráter discriminatório, revelador de um viés de classe do educador/pesquisador. As práticas e valores culturais das pessoas pobres são facilmente etiquetadas como inaceitáveis, incorretas, devendo se estender uma "escada" para que os pobres transponham o fosso entre o seu mundo e o mundo "normal".

Entretanto, no que diz respeito às preocupações com a promoção da saúde, do desenvolvimento e da educação da criança, a consideração das condições socioeconômicas das populações atendidas pelas creches não deve jamais estar em segundo plano. $\mathrm{O}$ que se pretende sustentar no presente trabalho é que a creche pode ter um impacto além da contribuição à educação da criança e, portanto, pode ser vista também como estratégia de elevação da qualidade de vida da população, assumindo um importante papel em contribuir para prover apoio às famílias e quebrar ciclos de violência doméstica, baixa escolaridade e reorganização de valores e práticas de criação. Mais do que isso, pretende-se demonstrar que, em certas condições, a creche é o único lugar onde essas questões podem ser trabalhadas, em vista do acesso facilitado às famílias, especialmente às mães, agentes privilegiados na promoção à saúde e à educação das novas gerações.

A posição proposta neste trabalho apóia-se na teoria ecológica do desenvolvimento de Bronfenbrenner (1996; 1995), que propõe uma multiplicidade de influências ambientais sobre o desenvolvimento da criança, sendo o ambiente concebido como subsistemas interligados, exercendo mútuas influências entre as partes. Micro, meso, exo e macrossistemas são instâncias do ambiente com efeitos no comportamento e desenvolvimento humanos. Enquanto as interações humanas diretas 
ocorrem nos microssistemas (casa, creche, grupo de vizinhança), eventos ocorridos em ambientes distantes, nos quais é possível que a criança jamais venha a estar (como o trabalho dos pais, por exemplo) podem afetar a sua vida, constituindo exossistemas. Também as relações entre os diferentes microssistemas, uma instância do ambiente denominada mesossistema, são uma importante fonte de influência no desenvolvimento da criança. A teoria ecológica de Bronfenbrenner, embora destacando o papel das díades como o contexto em que a maioria das interações ocorre, sujeita-as à influência de terceiros elementos, de modo que as interações que uma mãe estabelece com seu filho são moduladas pelas relações existentes entre a mãe e o pai, enquanto parceiros de um relacionamento conjugal.

$\mathrm{Na}$ concepção ecológica de desenvolvimento, de Bronfenbrenner (1996; 1995), casa e instituição de educação infantil interconectam-se num mesossistema, e os eventos que ocorrem em cada local afetam o outro. Por outro lado, as políticas públicas relativas a educação, emprego, segurança e outros aspectos relevantes da vida social, ainda que estejam distantes das vidas cotidianas das pessoas (exossistema), são capazes de influenciar suas trajetórias desenvolvimentais.

É nessa perspectiva que se coloca o presente trabalho, com o objetivo de examinar a relação creche-família, buscando explorar as possibilidades da creche de desempenhar algum papel nas políticas de elevação da qualidade de vida das populações urbanas.

\section{Participantes}

\section{Método}

O trabalho foi realizado com 90 mães usuárias de duas creches da região de Novos Alagados. Essa região localiza-se no Distrito Ferroviário da Cidade do Salvador (Bahia) e é constituída por um agrupamento urbano construído sobre a maré (palafitas). Ao longo dos anos, vêm sendo realizados aterros nessas áreas, havendo já grande número de casas em terreno firme. É densamente ocupada por casas de baixo padrão de construção, muitas ainda inacabadas.

\section{Contexto do estudo}

A pesquisa foi conduzida em campo por uma das autoras, membro da equipe técnica de umas das creches, subvencionada pela AVSI (Associação Voluntários para o Serviço Internacional). Essa instituição vêm atuando no bairro há vários anos, buscando elevar a qualidade de vida da população local, através do fornecimento de equipamentos e serviços de educação e saúde e da mobilização comunitária. De acordo com pesquisa realizada em 1993, pela AVSI, nesta região habitam, em condições precárias, por volta de 12.000 pessoas, sendo quase $60 \%$ destas menores de 18 anos, e mais de 2.000 crianças de zero a seis anos. Cerca de três quartos dos casais vivem juntos informalmente e a mulher, em mais da metade dos domicílios, é a única responsável pela manutenção da família.

As relações homem/mulher, conforme os resultados dessa pesquisa (AVSI, 1993), são instáveis e são constantes os episódios de violência (principalmente por parte dos homens). Estes relacionamentos homem/mulher são identificados pela AVSI como um dos problemas fundamentais da crise da família. Além disso, a iniciação sexual das crianças é precoce e, muitas vezes, traumática (grupos de adolescentes iniciam os mais novos de forma inadequada e violenta na prática sexual, inclusive homossexual). Todos estes fatos, somados ao modelo de relações familiares presentes na região, tornam ainda mais difícil para os jovens criarem relacionamentos afetivos e equilibrados que possam fundamentar um vínculo familiar duradouro.

Outras questões agravantes para a população feminina do bairro, levantadas pela pesquisa realizada pela AVSI são as seguintes: alta incidência de alcoolismo, aborto, esterilização e renúncia da maternidade (entrega dos filhos a outros para serem criados) e abandono dos filhos. Ao lado do abandono, é alta a incidência de negligência e abuso aos filhos, expressa na alta freqüência de agressões às crianças.

As creches a partir das quais as mães usuárias foram contatadas têm por critério atender crianças residentes na região e cujas mães trabalhem fora de casa. Além disso, essas instituições abrem precedentes para crianças com carências nutricionais, ou que demonstrem poucos cuidados físicos em termos de higiene e vestuário (dados que indicam um alto grau de miserabilidade ou descaso). No geral, elas apresentam um trabalho que busca um atendimento de qualidade às crianças e respectivas famílias, havendo um interesse constante de integração com a comunidade local. Há, portanto, uma formação continuada dos educadores e uma preocupação com a realização de um trabalho educacional conjunto com as famílias. $\mathrm{O}$ relacionamento dos educadores com as crianças é bom, em geral, mas é evidente que o número elevado de crianças por classe (cerca de 30 nas turmas de maiores de três anos) prejudica o desenvolvimento de atividades e a atenção mais individualizada fornecida pelo educador. As instituições contam com doações de pessoas físicas, com contribuições de organizações não governamentais estrangeiras, com uma taxa mensal simbólica cobrada dos pais das crianças e também com a Prefeitura Municipal de Salvador, que custeia, numa das creches, o pagamento de alguns funcionários, e na 
outra, a compra de alimentos, material didático e de limpeza.

Com respeito à relação com a família, a equipe técnica da creche (geralmente a diretora ou psicóloga) faz uma entrevista com os pais ou responsáveis pelas crianças tanto na inscrição para seleção quanto na matrícula. São também realizadas reuniões mensais com os pais, separadamente por grupo, o que favorece a comunicação a respeito do desenvolvimento de cada criança individualmente e também sobre o trabalho desenvolvido na creche. Nas reuniões com os pais são discutidos, inclusive, temas relativos à educação, saúde, nutrição etc.

O contato da equipe técnica da creche com as famílias também é estabelecido diariamente nos horários de entrada e saída das crianças. Quando aparece algum problema com a criança (desenvolvimento lento, dificuldades de adaptação, forte agressividade, entre outros), são realizadas entrevistas de acompanhamento. Além disso, em uma das creches, os pais (principalmente as mães) colaboram com a limpeza das instalações durante um turno de seis horas uma vez ao mês.

\section{Delineamento}

Este trabalho, de caráter exploratório, é parte de um estudo maior, que utiliza estratégias combinadas de abordagens qualitativa e quantitativa, com o interesse em obter um perfil da população da região de Novos Alagados. O foco de interesse foi a obtenção de um painel do contexto socioeconômicocultural, com ênfase nas concepções mais gerais de mães usuárias de creche sobre educação de filhos.

\section{Instrumentos}

Para atingir os objetivos do presente estudo, foram utilizados dois instrumentos. Eles foram elaborados com base na literatura sobre o papel das concepções parentais, e a partir das observações realizadas no desenvolvimento das atividades profissionais de uma das pesquisadora no local, e também através das entrevistas-piloto.

$\mathrm{O}$ primeiro instrumento foi uma entrevista estruturada contendo questões formuladas previamente, incluindo temas relativos a dados de identificação e da família; responsabilidade pela criação da criança; educação da criança; concepções de criança, filho, desenvolvimento infantil, ensino, aprendizagem e creche.

O segundo instrumento consistiu em entrevista semi-estruturada e gravada, visando a apreender melhor as concepções das mães. Através dela, foram aprofundados os mesmos temas abordados na entrevista anterior.

\section{Procedimentos}

\section{Coleta de dados}

$\mathrm{Na}$ fase-piloto da pesquisa, foi realizada entrevista semi-estruturada e gravada com duas mães, abordando temas relativos às perguntas iniciais da pesquisa, visando a detectar aspectos relevantes a serem incluídos nas entrevistas definitivas. A partir disto, foi construído o roteiro da primeira entrevista que, após ser testada com quatro mulheres usuárias de creche, sofreu ainda pequenas modificações.

Tendo em mãos a lista de crianças matriculadas em cada uma das creches foi realizado o sorteio da amostra, numa proporção de $50 \%$ das crianças. Após a escolha aleatória, foi realizado convite verbal, por uma das pesquisadoras, a cada uma das mães das respectivas crianças sorteadas, para que participassem de uma entrevista sobre as suas idéias relativas à educação de filhos e sobre creche.

A entrevista foi aplicada por uma das pesquisadoras nas próprias creches, imediatamente após o convite ou em data agendada conforme possibilidade da mãe respondente. Em seguida, dos 90 casos, foram escolhidos três para participarem da segunda entrevista (realizada nas respectivas creches). Essas mães foram escolhidas intencionalmente, para representarem situações prototípicas dos tipos de família mais comumente encontradas nos ambientes urbanos contemporâneos, a saber, famílias monoparentais, famílias nucleares e famílias extensas. Outros aspectos considerados foram o número de filhos, escolaridade, idade, situação financeira e trabalho. Em seguida, foram transcritas as gravações dessas últimas entrevistas.

\section{Análise dos dados}

Os dados obtidos na primeira entrevista foram submetidos a uma análise estatística descritiva, obtendo-se as percentagens das respostas encontradas. Nas questões que receberam respostas múltiplas, foram obtidas duas percentagens, uma com relação ao número de casos e outra com relação ao número de respostas encontradas.

A análise dos dados da segunda entrevista, correspondendo aos três casos selecionados intencionalmente, teve um caráter qualitativo e complementar. As pesquisadoras selecionaram trechos relativos a cada dimensão investigada, que foram usados para ilustrar os dados obtidos na amostra total, de modo a fornecer exemplos detalhados das concepções encontradas, situando-as em uma história pessoal, embora não necessariamente representativa das histórias do conjunto das pessoas que compuseram a amostra.

\section{Resultados}

\section{Condições socioeconômicas das famílias}

O nível de escolaridade observado na população é baixo, com a maioria da amostra na faixa do primeiro 
grau. Esses resultados diferem do observado na população brasileira: as faixas de escolaridade mais baixas e mais altas têm freqüências inferiores às encontradas na população brasileira. Por exemplo, na amostra de Novos Alagados, 8,9\% das mulheres e $8,4 \%$ dos homens nunca foram a escola (Tabela 1), enquanto na população brasileira esses números são 13,2 e 13,6\%, respectivamente (IBGE, 2002). A maior discrepância, entretanto, é encontrada no grupo de escolaridade superior (completa ou incompleta) que é zero entre os homens e de $1,1 \%$ entre as mulheres da amostra, enquanto as freqüências nacionais são 17,5\% entre os homens e $20,4 \%$ entre as mulheres.

A maioria das mães $(68,9 \%)$ possui alguma atividade remunerada, em ocupações que não requerem muita qualificação; das 63 mães que trabalham, $61,9 \%$ atuam como empregadas domésticas, babás, faxineiras e lavadeiras. As outras $38,1 \%$ trabalham como educadoras de creche, monitoras de escola, costureiras ou auxiliares de costura, vendedoras ambulantes, manicures, caixas de restaurante, guardadoras de automóvel, lavadoras de garrafa, cozinheiras de restaurante, dentre outros.

Tabela 1: Distribuição percentual da população conforme a escolaridade

\begin{tabular}{lcc}
\hline Escolaridade & $\begin{array}{c}\text { Mãe } \\
\text { \% }\end{array}$ & $\begin{array}{c}\text { Pai } \\
\mathbf{\%}\end{array}$ \\
\hline Nunca foi à escola & 8,9 & 8,4 \\
Até a $4^{\text {a }}$. série do $1^{\circ}$. Grau & 32,2 & 35,2 \\
Da $5^{\text {a }}$ à $8^{\text {a }}$. série do $1^{\circ}$. Grau & 44,4 & 43,7 \\
$2^{\circ}$. Grau incompleto ou mais & 14,5 & 12,7 \\
Número de casos & $\mathbf{( 9 0 )}$ & $\mathbf{( 7 1 ) *}$ \\
\hline Total & $\mathbf{1 0 0 , 0}$ & $\mathbf{1 0 0 , 0}$ \\
\hline * Exclui 19 casos em que o pai era falecido ou a mãe não soube informar a \\
escolaridade do pai da criança.
\end{tabular}

No que diz respeito aos pais, grande parte deles trabalha $(62,2 \%)$. Trata-se de uma atividade profissional bastante variável mas, no geral, eles também desempenham tarefas manuais que requerem pouca qualificação, tais como pedreiro ou ajudante de pedreiro, carregador de mercadoria, marceneiro, carpinteiro, pintor, agente de limpeza, serviços gerais, ajudante de mudança, dentre outras; ou, ainda, atuam como vigia, porteiro de prédio, policial militar, motorista, cobrador de ônibus, entre outras ocupações assemelhadas quanto ao nível de qualificação requerida.

No geral, o trabalho é exercido em condições precárias, no que diz respeito aos direitos trabalhistas e à proteção social ao trabalhador. Apenas $25,4 \%$ das mães possuem carteiras de trabalho assinadas. Para os pais, esse percentual eleva-se a $58,0 \%$. A natureza do vínculo empregatício, no caso das mães $(71,2 \%$ trabalham para pessoas físicas) revela que o trabalho doméstico é a principal ocupação das mulheres. A maior parte das mães e a totalidade dos pais que trabalham têm jornadas semanais de 40 horas ou mais.

De um modo geral, a renda familiar da população estudada é baixa, cerca de dois salários mínimos ou menos, em mais da metade dos casos (Tabela 2). Há dez por cento de casos em que a renda é inexistente, sobrevivendo a família através do fornecimento, por parte de algum familiar ou conhecido, de alguns gêneros alimentícios e/ou outros bens de consumo. Considerados separadamente (mãe ou pai) não houve casos de rendimentos acima de cinco salários mínimos, sendo a renda das mulheres mais baixa que a dos homens. Como a percentagem de mulheres solteiras chega a $43,4 \%$, pode-se inferir um grande número de famílias com renda muito baixa, próxima do salário mínimo. 
Tabela 2: Distribuição percentual da amostra por remuneração mensal

\begin{tabular}{lccc}
\hline Renda & $\begin{array}{c}\text { Mãe } \\
\text { \% }\end{array}$ & $\begin{array}{c}\text { Pai } \\
\text { \% }\end{array}$ & $\begin{array}{c}\text { Renda } \\
\text { Familiar }\end{array}$ \\
\hline Até 1 salário mínimo & 54,6 & 15,9 & 29,3 \\
Mais de 1 a 2 salários mínimos & 12,1 & 29,8 & 33,2 \\
Mais de 2 a 5 salários mínimos & 2,2 & 16,5 & 25,3 \\
Mais de 5 salários mínimos & 0 & 0 & 2,2 \\
Não possui renda & 31,1 & $37,8^{*}$ & $10,0 * *$ \\
\hline Total & $\mathbf{1 0 0 , 0}$ & $\mathbf{1 0 0 , 0}$ & $\mathbf{1 0 0 , 0}$ \\
Número de casos & $\mathbf{( 9 0 )}$ & $\mathbf{( 9 0 )}$ & $\mathbf{( 9 0 )}$ \\
* Inclui casos em que ou o pai é falecido ou a mãe não sabe informar. \\
** Não possuem renda (em dinheiro) mas, em alguns casos, recebem gêneros alimentícios e/ou \\
outros bens de consumo com certa regularidade.
\end{tabular}

Nessas condições de renda, a fome não é incomum, como se vê em alguns depoimentos:

“... tem dia que eu não tenho pra dar a eles, tem dia que eu não tenho. [...] tem vez que eu tenho merenda pra dar a eles dia de sábado dentro de casa e domingo, tem dia que não tem nem merenda. Eles passa o dia com o café que eles toma de manhã. Se tiver pra comer 12:00 hora tem e se num tiver tem que esperar o pai dele [referindo-se ao filho de dois meses que estava em seu colo] chegar da feira pra trazer. Tem dia que ele traz da feira, tem dia que não traz." (Jacira)

"... tem dia que a gente tem o pão, não tem o leite. Tem dia que a gente tem o feijão e não tem o arroz. Mas a gente vai levando a vida." (Andréa).

As condições de pobreza são muito graves: um terço da população vive em precárias casas de madeira, algumas fixadas sobre a maré. Com respeito à organização familiar observada foram encontradas 43,4\% das mães solteiras, enquanto 38,9\% mantêm união consensual e 14,4\% dos casos casadas. Ou seja, um pouco mais da metade das mães $(53,3 \%)$ são casadas ou unidas consensualmente com um homem. Tal cônjuge (de uniões formais ou não) é, na grande maioria dos casos $(95,8 \%)$, o pai da criança referência a partir da qual a mãe foi solicitada nesta pesquisa.

Em 48,9\% dos casos, o pai e a mãe não moram juntos numa mesma casa, sendo variável o contato de cada pai com os filhos. Nesses casos, como se vê na Tabela 3, 41,8\% das crianças nunca ou raramente vêem os pais. Considerando o total de crianças filhos das 90 mães, cerca de $20 \%$ encontram-se nessa situação.

Tabela 3: Distribuição percentual da quantidade de contato do pai com a criança quando os pais não moram juntos

\begin{tabular}{|c|c|}
\hline Quantidade de contato do pai com a criança & $\%$ \\
\hline Nunca/raramente & 41,8 \\
\hline Pelo menos uma vez por semana & 39,6 \\
\hline Menos de uma vez por semana & 18,6 \\
\hline Total & 100,0 \\
\hline Número de casos & (43) \\
\hline
\end{tabular}

Tomando os dados relativos à realidade brasileira em geral como referência, nem o número de moradores das casas é grande, e nem o número de filhos é elevado. No que diz respeito à quantidade de moradores, ela varia de dois a dez, sendo que, em cerca de três quartos dos casos $(76,7 \%)$, residem até cinco pessoas (sendo a média de 4,4 pessoas por casa e desvio padrão de 1,7).
Com relação aos filhos, encontrou-se uma frequiência variando de um a dez. Cerca de três quartos dos casos $(73,3 \%)$ possuem até três filhos, havendo uma média de 2,63 filhos por mãe (desvio padrão: 1,69). Nem todos os filhos moram na casa com a mãe, alguns residem com a avó no interior do Estado, e outros em casas separadas, por já serem adultos independentes, dentre outras razões. Em 
$80,0 \%$ dos casos residem na casa até três filhos (média 2,3; desvio padrão 1,4).

\section{O lugar da creche na vida das famílias}

A literatura nacional tem relatado freqüentemente (Haddad, 1987,1991; Oliveira, Mello, Vitória e Rossetti-Ferreira, 1992; Chaguri, 1998; Mello, 1998), as dificuldades existentes na relação entre a creche e a família, pontuada por conflitos e sentimentos ambíguos de ambas as partes. Do lado das mães, culpa, hostilidade, medo de perder o amor da criança, sentimentos de inferioridade, entre outros, são ocorrências comuns. Do lado da creche, a maior parte dos estudos tem relatado crenças e práticas de desvalorização das famílias, com desprezo pelas suas idéias e hábitos.

Os resultados aqui apresentados confirmam outros estudos (Haddad, 1987, 1991; Oliveira e cols., 1992), quanto ao sentimento de dívida das mães em relação à creche. Mas a visão encontrada é altamente positiva. A creche é vista como uma oportunidade para a criança, como o melhor lugar em que a criança poderia estar. A quase totalidade das mães $(96,7 \%)$ considera que o fato de a criança freqüentar este tipo de instituição não prejudica em nada o apego da mãe ao filho e também do filho à mãe; ao contrário, em muitos casos, a distância entre mãe e criança os tornaria mais saudosos, o que valorizaria mais o tempo em que permanecem juntos.

Sobre a opção de colocar o filho na creche, quase dois terços dos casos $(63,3 \%)$ afirmam que, se pudessem escolher outra alternativa, mesmo assim optariam por colocar o filho na creche. Como se vê na Tabela $4^{4}$, dentre as categorias que obtiveram maior número de respostas, podem ser destacadas aquelas relacionadas a aspectos não específicos de creche, como local seguro para a permanência do filho, um segundo lar ou como se fosse a casa da criança e ajuda para as mães poderem trabalhar; outros aspectos mais específicos mencionados foram "local onde a criança é educada/estuda/alfabetizada" e "local onde a criança se desenvolve/aprende".

Tabela 4: Distribuição percentual das respostas das mães diante da questão sobre o que significa creche para elas

\begin{tabular}{lcc}
\multicolumn{1}{c}{ Respostas das mães } & $\begin{array}{c}\text { \% } \\
\text { (por casos) }\end{array}$ & $\begin{array}{c}\text { \% } \\
\text { (por respostas) }\end{array}$ \\
\hline Local seguro para a permanência do filho & 37,4 & 19,4 \\
Um segundo lar ou como se fosse a casa da criança & 31,9 & 16,4 \\
Local onde a criança é educada/estuda/é alfabetizada & 30,8 & 15,8 \\
Ajuda para as mães poderem trabalhar & 26,4 & 14,4 \\
Local onde a criança se desenvolve/aprende & 20,9 & 11,2 \\
Local onde a criança convive com outras pessoas & 8,8 & 4,8 \\
Local onde brinca & 8,8 & 4,8 \\
Local em que as crianças recebem cuidados físicos básicos & 7,7 & 4,2 \\
Oferece carinho/amor/atenção & 6,6 & 3,6 \\
É importante/muito boa & 6,6 & 3,6 \\
Outros & 3,3 & 1,8 \\
\hline Total & - & $\mathbf{1 0 0 , 0}$ \\
& Número de & Número de \\
& casos & respostas \\
\hline
\end{tabular}

No que diz respeito a sentimentos negativos, entretanto, os dados deste estudo são diferentes dos encontrados na literatura. Praticamente não há respostas relatando opiniões ou sentimentos negativos em relação à creche. É possível que esse resultado seja uma consequiência das circunstâncias em que a coleta de dados ocorreu. De fato, a entrevistadora era membro da equipe de uma das creches, vista, possivelmente, como alguém capaz de punir eventuais insatisfações ou "ingratidão". Essa condição, capaz de prejudicar a exatidão dos resultados quanto a alguns aspectos, é vista como inevitável, dada a vantagem resultante de uma inserção do pesquisador no contexto da pesquisa.

Seja pela ausência de sentimentos negativos, seja pelo receio de expressá-los, a reflexão que se pode fazer sobre esse resultado sugere que a creche tem um papel crucial na vida dessas pessoas, identificado, em casos extremos, com a própria sobrevivência da criança.

Em geral, as casas são pequenas e pouco atrativas e muitas são construídas sobre áreas alagadas pelas marés (palafitas). As taxas de criminalidade são altas e a violência é uma experiência cotidiana. Muitas mães são aterrorizadas pela possibilidade de seus 
filhos caírem na maré (zona de lama alagada a cada maré cheia), ou serem atropelados, ou serem vítimas acidentais de tiros e outras formas de violência e, até mesmo, presenciarem cenas impróprias, "indecências" ou violência. Portanto, para a realidade deste bairro, um aspecto relevante atribuído à creche é a segurança, o que significa inclusive a diminuição do risco de mortalidade infantil.

Esse fato pode ser ilustrado com a fala de Jacira: “... aqui na creche eles não estão arriscando a vida deles [...] eu sei que meus filho aqui na creche tão guardado, tão fora de perigo, porque ali aonde eu moro, tudo é muito perigoso".
Na verdade, a avaliação da creche, de sua utilidade e valor pelas mães, é bastante genérica. Como se vê na Tabela 5, a categoria de resposta mais freqüente quando se perguntou sobre quais aspectos consideram mais importantes para que uma creche seja um bom local para as crianças foi "educação e bons educadores", uma resposta genérica, compatível com usuários com poucos conhecimentos sobre educação, psicologia, educação infantil etc.. É possível que também essa resposta seja afetada pela posição da pesquisadora como funcionária da creche, na medida em que representa um tipo de valorização do trabalho da equipe.

Tabela 5: Distribuição percentual das respostas das mães diante da questão sobre quais são as coisas mais importantes para que uma creche seja um bom lugar para a criança

\begin{tabular}{lcc}
\hline Respostas das mães & $\begin{array}{c}\text { \% } \\
\text { (por casos) }\end{array}$ & $\begin{array}{c}\text { \% } \\
\text { (por respostas) }\end{array}$ \\
\hline Educação/bons educadores & 74,8 & 30,0 \\
Limpeza/organização & 35,2 & 14,0 \\
Afetividade/tratar bem & 28,6 & 12,0 \\
Espaço físico/brinquedos/brincadeiras & 22,0 & 10,0 \\
Alimentação & 20,9 & 9,5 \\
Assistência médica & 17,6 & 8,0 \\
Alfabetização & 9,9 & 4,5 \\
Boa coordenação/administração & 6,6 & 3,0 \\
Outros & 22,0 & 9,0 \\
\hline Total & - & $\mathbf{1 0 0 , 0}$ \\
& N. de casos & N. de respostas \\
& $(\mathbf{8 9}) *$ & $(\mathbf{2 1 6})$ \\
\hline
\end{tabular}

* Exclui 1 caso em que a mãe não soube responder.

Como desvantagem para a criança que freqüenta creche, a grande maioria das mães $(84,4 \%)$ julga não haver nenhuma. As poucas respostas relatando desvantagens são referentes ao fato de a criança ficar longe dos pais ou parentes e, em alguns casos, a existência de uma taxa simbólica de contribuição. $\mathrm{Na}$ entrevista gravada com Jacira, embora ela considere a creche muito boa, menciona que

“... tem muita gente aí que não reconhece o que o pessoal da creche faz pelo filho. Ainda sai esculhambando que as tia da creche não presta, que os menino da creche são maltratado. Eu nunca falei isso, eu, graças a Deus, eu não tenho o que falar da creche. Me dou muito bem com a creche também, meus filho não são maltratado, ao contrário ..."
Uma avaliação igualmente positiva é vista no relato de Andréa. Para ela, creche

“... é uma coisa muito boa. Tem educação, a criança aprende tanta coisa na creche: o horário de tomar banho, o horário de almoçar, o horário de orar (...) minha filha já se desenvolveu o suficiente na creche (...) é creche que tem médico, é creche que tem bom fim, tem uma boa professora, minha filha já sabe fazer o nome dela todo, já sabe escrever. É uma criança sadia, nunca tive um motivo pra poder fazer uma queixa sobre a creche, nenhuma. (...) ... uma bênção de Deus, sou muito feliz com a minha filha na creche. Agradeço muita coisa aqui a creche (...) a creche trouxe boas coisa pra minha filha e se amanhã ou depois minha filha for crescendo e for vivendo (...) eu acho 
que ela nunca vai esquecer a creche e nem eu. Muito grata."

Por outro lado, há evidências de fatores de risco típicos de populações urbanas muito pobres, como alcoolismo, violência doméstica envolvendo cônjuges e crianças, abandono da escola, envolvimento com consumo e tráfico de drogas. A análise dos dados do presente estudo sugere que a creche pode ter um papel significativo em romper com ciclos de pobreza e violência. Considere-se, em conjunto, os dados referentes à história pessoal de duas participantes do estudo e o relato de seu contato com a creche.

Sobre uma comparação entre o modo como foi criada e o modo como cria seus próprios filhos, Jacira fala:

"- Ah, o que eu passei quando era pequena, eu acho que eu crio meus filhos muito diferente do que eu passei; eu sofri muito quando eu era pequena. Minha mãe me botou na casa de uma criatura, botou eu pra chamar a criatura de vó. Aí eu chamada a criatura de vó, a criatura chegou com um ferro pra me queimar. A marca que eu tenho, eu acho que é desse lado, ou é desse lado de cá que eu tenho a marca do ferro. A criatura me queimou, quebrou minha cabeça. Eu e minha irmã sofremos muito nas casas dos outros quando nós era pequena porque Mãe saía pra negócio de curtição, pra curtir com os pessoal da ... com negócio de homem na rua. Ela era moderna, aí gostava de tomar ... as birita dela e deixava a gente na casa dos outros. A gente sofria muito, a gente apanhava, a gente recebia nome, recebia praga que a criatura jogava em cima da gente e tudo. E nisso a gente foi crescendo só sendo magoada, sendo machucada pela mão dos outros, porque ela mesma não batia na gente, não. Mas a mulher que ela botou pra gente chamar de vó era que maltratava a gente. Mas o que eu passei eu não posso descontar nos meus filhos, né? Tem hora que eu pego meus filhos em casa pra bater, mas minha irmã chega pra mim e diz: "Você não deve, é, como é, você não deve descontar sua raiva nos meninos porque os meninos não têm nada a ver com o que a gente passou. As crianças não pediu pra vir ao mundo. Se você procurou, você tem mais de assumir e criar seus filho. Não é espancar seus filhos, jogar praga nos seus filho, xingar seus filhos, porque eles não têm nada a ver com o que a gente tá passando; eles não pediu pra vir ao mundo, Se a gente procurou é porque a gente quis, né?". Mas a gente não deve descontar a nossa raiva em cima dos meninos porque tem hora quando eu brigo com o pai dele, aí eu não vou em cima do pai dele, eu vou em cima dos menino, bato nos meninos. Aí Celinha vai lá em casa, tira os meninos da minha mão - "Não desconte sua raiva em cima dos meninos porque os meninos não têm nada a ver com isso ... Não é uma mulher desprezar seus filhos por causa de marido, não, maltratar seus filhos por causa de marido, não". E a mesma coisa eu digo com ela porque tem vez que ela pega os dela pra bater também dentro de casa, aí eu falo a mesma coisa que ela fala comigo, eu falo com ela também."

A fala de Jacira é eloqüente como ilustração de uma realidade que se configura como sistema fechado, o ciclo da violência doméstica. Ela não quer espancar seus filhos, quer educá-los do melhor modo possível. Ela sabe (da mesma forma que sua irmã) que não deve "descontar" nos filhos seus problemas. Ela aconselha sua irmã e vice-versa. Entretanto, os recursos pessoais podem ser poucos, insuficientes para reverter a tendência de transmissão intergeneracional da violência. Jacira e sua irmã são vítimas da negligência e abuso na infância e, possivelmente, carregam o fardo das sequielas comumente associadas a essas experiências. A transmissão intergeneracional de práticas de negligência, abuso e violência contra a criança é bem documentada na literatura; para as mães, observa-se uma cadeia que leva do maltrato na infância a um estilo de cuidado parental pobre ou, no caso de abuso sexual, a práticas agressivas de criação; para os homens, as experiências de vitimização na infância têm também consequiências em uma paternidade deficiente e, nos casos de abuso sexual, rejeitadora (Newcomb e Locke, 2001).

A creche pode ter um papel em quebrar esses ciclos. Especificamente no caso da violência doméstica, a redução da carga de trabalho da família, mais especificamente da mãe, pode resultar numa redução do nível materno de estresse e, por conseqüência, na melhoria da qualidade das interações entre mãe-criança. Também a interação com os trabalhadores da creche pode ter um papel nas concepções e práticas de cuidado. Novamente a fala de Jacira pode ilustrar esse ponto.

Jacira refere que os momentos de festa ajudam a conhecer o trabalho desenvolvido na creche. Inclusive, quando vai buscar os filhos, observa que as educadoras “...tão sentada lá no galpão com os menino cantando, tem umas que tá até dançando com os menino..."

Também Andréa fala sobre as observações que faz do trabalho da creche, dizendo:

“... a gente vai numa reunião, a gente entende que a criança quando chega (...) toma café, ora a criança vai toma é ... almoçar, ora a criança tem uma vida melhor. A gente vai aprendendo que na creche ninguém bate nela, ninguém faz violência com ela, com a criança. A criança vai estudando e vai aprendendo e com o ensinamento dentro de casa fica melhor e foi assim que eu aprendi na creche: olhando as coisa." 
É provável que o contato das mães com a creche enriqueça suas experiências e conhecimentos sobre o cuidado à criança, através da observação de outras pessoas e da reflexão possibilitada pelas oportunidades de discutir as condições de seus filhos. A presença da creche pode funcionar com um elemento que afeta a díade mãe-filho, nos termos de Bronfenbrenner (1996).

\section{Discussão e conclusões}

Os dados aqui apresentados dão apoio à hipótese de que, nas condições socioeconômico-culturais consideradas, a creche pode ter um papel de desencadear e apoiar mudanças substanciais nas práticas de criação de filhos, com repercussões importantes no desenvolvimento da criança.

Quatro são as condições relevantes consideradas: a) pobreza extrema; b) baixa escolaridade; c) estrutura de família prevalente; d) condições pessoais de vulnerabilidade. No primeiro caso, o baixíssimo nível de renda das famílias põe em risco a sobrevivência da criança no que diz respeito a alimentação, saúde e segurança. A escassa disponibilidade de alimentos, em quantidade e qualidade, a precariedade das casas e a insuficiência de dinheiro para utilizar adequadamente os serviços de saúde (transporte para ir aos serviços de saúde, dinheiro para a compra de medicamentos e de suprimentos alimentares quando necessários) aumentam as probabilidades de mortalidade infantil ou de sequielas resultantes de cuidados médicos insuficientes. A inserção da criança na creche reduz alguns desses problemas, particularmente alimentação e saúde, em vista da possibilidade de uso da creche como "ponto" de fornecimento de alguns desses serviços. De fato, os serviços de saúde aplicam vacinas nas creches, e profissionais de saúde estão disponíveis em algumas delas para cuidados de atenção primária.

O segundo, a baixa escolaridade das famílias, pode ter uma repercussão indireta sobre a capacidade dos pais de cuidar adequadamente dos seus filhos, na medida em que reduz o acesso e compreensão das informações veiculadas pelos serviços de saúde e pela mídia, em geral. A baixa escolaridade reduz o necessário apoio da família às atividades acadêmicas da criança, na medida em que a mãe pode não compreender bem tarefas escolares do seu filho, instruções da escola e seus programas, reduzindo a sua capacidade de influir nos currículos escolares (a partir dos quatro anos, as creches funcionam também como pré-escolas, prescrevendo eventualmente tarefas a serem realizadas em casa). Mesmo nos níveis iniciais da educação infantil (zero a três anos), a baixa escolaridade dos pais pode dificultar o entendimento de orientações para um tratamento mais responsivo às suas crianças, o qual, por sua vez, pode afetar diversas áreas do desenvolvimento. Esse fator também está presente na menor eficiência de práticas de saúde, uma vez que as famílias têm reduzida capacidade de dialogar com os profissionais de saúde e entender e/ou discutir suas orientações.

O terceiro fator, a estrutura de família prevalente, é conhecido na literatura como um fator de risco para a criança. Quase a metade das famílias é formada pela mãe apenas ou por casais não estáveis no tempo (o homem é o pai da criança mais nova). Seja pela excessiva carga de trabalho resultante de cuidar dos filhos e trabalhar, ao mesmo tempo, seja pelos riscos associados à paternidade adotiva instável, as condições da família não são suficientes para o adequado apoio à tarefa de criar os filhos.

$\mathrm{O}$ quarto fator refere-se à existência, bastante comum, de uma série de problemas ligados às condições pessoais dos pais, como violência, consumo de drogas, principalmente álcool, conduta criminosa, negligência e abuso dos filhos. Embora essas condições não sejam típicas dessa população, no sentido de representarem a maioria das pessoas, elas são bastante comuns, pelo menos um dos problemas relacionados, ocorrendo em uma fração expressiva (não determinada nesse estudo) da população.

Todas essas condições juntas resultam num enfraquecimento da capacidade da família, especialmente das mães, de cuidar adequadamente de seus filhos. Em outro trabalho, Moreira (1999) relata as concepções dessa população sobre criação de filhos. A autora destaca nesse trabalho a relativa pobreza das mães no domínio de estratégias de favorecimento ao desenvolvimento da criança, em todos os domínios considerados; acadêmico, social e emocional. Assim, condições como pobreza, baixa instrução, desorganização familiar, ausência ou precariedade de redes sociais de suporte, não são determinantes de resultados desenvolvimentais deficientes. Entretanto, estas são condições que estão associadas a maus resultados, na medida em que induzem a uma descrença na própria capacidade de influenciar na criação dos filhos.

No todo, essas condições configuram uma situação clara de risco ao desenvolvimento. Propõe-se que o acesso à creche, em alguns casos, pode ser uma das poucas oportunidades de rompimento de ciclos de perpetuação da violência. A entrada de uma criança numa creche, pelo menos numa creche com padrões mínimos de qualidade, pode representar um elemento que introduz um veículo de acesso constante às famílias, na disponibilidade de recursos materiais diretos, no suporte ao trabalho feminino e melhoria de renda das famílias e, acima de tudo, na presença de 
uma interlocução consistente sobre o cuidado da criança.

Esse caminho pode ser delineado em quatro áreas, direta ou indiretamente afetadas pela entrada da criança na creche:

a) Apoio para o trabalho feminino. Como visto nos dados apresentados nesse estudo, o trabalho feminino parece essencial para a elevação de renda da população. Nas condições socioeconômicas prevalentes (instrução, renda, estrutura da família, organização social e política), o emprego doméstico feminino aparece como uma das poucas alternativas nas condições observadas, uma situação em que a disponibilidade de cuidado para as crianças é, obviamente, indispensável.

b) Fornecimento/discussão de modelos/referenciais de educação. Como já comentado acima, a creche pode oferecer e discutir modelos de cuidado à criança, nos campos dos cuidados físicos e de saúde, nas estratégias de controle e disciplina, na circulação e questionamento de valores tradicionais ou "modernos", enfim, a creche pode constituir-se como um interlocutor que reflete as experiências de vida de cada um, permitindo que elas sejam repensadas e, eventualmente, modificadas.

c) Aumento de conhecimento sobre educação e psicologia. Ao lado das teorias parentais sobre educação, desenvolvidas como conhecimento de senso comum, compartilhado socialmente, a relação com a creche pode criar oportunidades de acesso a informações científicas sobre criança e desenvolvimento. Além do acesso direto possibilitado pelas ocasiões de palestras e instruções de serviço, pode-se estimar uma ativação da atenção às informações que circulam no dia-a-dia das pessoas, em revistas e jornais, nas novelas, nas campanhas publicitárias etc.

d) Engajamento na consecução de objetivos comunitários. Finalmente, a inclusão na creche pode contribuir para um reforço do senso de poder como agente social, na medida em que a experiência contribui para a formação de grupos com objetivos comuns, os quais podem se estender além dos muros da instituição, na ação relacionada a objetivos comunitários.

Assim, sugere-se que, mesmo a "creche ideal" com ótimas condições de funcionamento, deve destacar um lugar especial para a relação creche-família, em que esta última seja não apenas o cidadão que tem o direito à creche de boa qualidade, mas, em certos casos, uma camada social que será afetada pela creche e, portanto, deve ser objeto de consideração e políticas especialmente planejadas. Em poucas palavras, a creche pode ser um recurso (às vezes o único) para quebrar o ciclo de pobreza, marginalização, doença e violência.

\section{Referências}

AVSI (1993). Perfil sócio-econômico da população de Nova Esperança (Novos Alagados). Relatório não publicado da Associação Voluntários para o Serviço Internacional.

Brasil/IBGE (2002). Brasil em sintese. (http://www.ibge.net/brasil _em_sintese, 16/06/2002).

Bronfenbrenner, U. (1995). Developmental ecology through space and time: a future perspective. Em P. Moen, G. H. Elder \& K. Lüscher (Orgs.), Examining lives in context (p. 599-618). Washington: American Psychological Association.

Bronfenbrenner, U. (1996). A ecologia do desenvolvimento humano: experimentos naturais e planejados. Porto Alegre: Artes Médicas. (Original publicado em 1979).

Chaguri, A. C. (1998). Pais e educadores: a fome de conhecimento um do outro. Em M. C. Rossetti-Ferreira, A. M. Mello, T. Vitória, A. Gosuen \& A. C. Chaguri (Orgs.), Os fazeres na educação infantil (p. 21-25). São Paulo: Cortez.

Connel, R. W. (1995). Pobreza e educação. Em P. Gentili (Org.), Pedagogia da exclusão: crítica ao neoliberalismo em educação. Petrópolis: Vozes.

Geis, R. M. (1994). Criar ou educar crianças? Estudo das representações de mães e de educadoras sobre o papel da creche. Tese de doutorado, Instituto de Psicologia: Universidade de São Paulo. São Paulo, SP.

Haddad, L. (1987). A relação creche-família: relato de uma experiência. Cadernos de Pesquisa, 60, 70-78.

Haddad, L. (1991). A creche em busca de identidade. São Paulo: Edições Loyola.

Lamb, M. E. \& Sternberg, K. J. (1992). Sociocultural perspectives on nonparental child care. Em M. E. Lamb, K. J. Sternberg, C. Hwang \& A. G. Broberg (Orgs.), Child Care in Context. Hillsdade: LEA.

Mello, A. (1998). Um diálogo com os diretores de creches e préescolas. Em M.C. Rossetti-Ferreira, A. M. Mello, T. Vitória, A. Gosuen \& A. C. Chaguri (Orgs.), Os fazeres na educação infantil (p. 3-36). São Paulo: Cortez.

Moreira, L. M. V. (1999). Concepções de mães usuárias de creche sobre educação de filhos. Dissertação de mestrado não publicada, Faculdade de Educação, Universidade Federal da Bahia. Salvador, BA.

Newcomb, M. D. \& Locke, T. F. (2001). Intergenerational cycle of maltreatment: a popular concept obscured by methodological limitations. Child Abuse \& Neglect, 25, 1209-1240.

Oliveira, Z. M., Mello, A. M., Vitória, T. \& Rossetti-Ferreira, M. C. (1992). Creches: crianças, faz de conta e cia. Rio de Janeiro: Vozes.

Rossetti-Ferreira, M. C., Amorim, K. S \& Vitória, T. (1994). A creche enquanto contexto possível de desenvolvimento da criança pequena. Revista Brasileira de Crescimento $e$ Desenvolvimento Humano, 4(2), 35-40.

Sousa, A. M. C. (1996). Educação infantil: uma proposta de gestão municipal. Campinas: Papirus. 
Notas:

${ }^{1}$ Este artigo é baseado em dados apresentados na Dissertação de Mestrado Concepções de mães usuárias de creche sobre educação de filhos, apresentada ao Programa de Pós-Graduação em Educação da UFBa, pela primeira autora, sob a orientação da segunda.

${ }^{2}$ Cópias do roteiro podem ser obtidas com as autoras.

${ }^{3}$ Nomes fictícios.

${ }^{4}$ A tabela utiliza dados de respostas múltiplas para a mesma questão. Assim, o número de respostas é maior que o número de casos. O cálculo de percentagens por casos (primeira coluna) indica que a resposta "Educação/bons educadores" foi dada por $74,8 \%$ das mães enquanto o cálculo por número de respostas permite saber que essa categoria representa $30 \%$ de todas as respostas.

Sobre as autoras

Lúcia Vaz de Campos Moreira: Pontifício Instituto João Paulo II sobre Matrimônio e Família. Bolsista Capes. Endereço para correspondência: Rua Guadalajara, 15, apto. 101, Morro do Gato - 40140-460, Salvador, Bahia.

Eulina da Rocha Lordelo: Bolsista CNPq. Universidade Federal da Bahia / Departamento de Psicologia/Faculdade de Educação. 